\title{
Re-Treatment Strategies for Neovascular AMD: When to Treat? When to Stop?
}

\author{
Sengul Ozdek ${ }^{1}$ and Mehmet Cuneyt Ozmen² \\ ${ }^{1}$ Gazi University, School of Medicine, Department of Ophthalmology, Ankara \\ ${ }^{2}$ Yenisehir State Hospital, Department of Ophthalmology, Kahramanmaras
}

Turkey

\section{Introduction}

Age-related macular degeneration (AMD) is a leading cause of severe, irreversible vision impairment in developed countries (Friedman et al., 2004; Klein et al., 1992). Although an estimated $80 \%$ of patients with AMD have the non-neovascular form, the neovascular form is responsible for almost $90 \%$ of severe visual loss (visual acuity 20/200 or worse) resulting from AMD (Ferris et al., 1984). There was no effective treatment for most of the neovascular AMD lesions till 2004. By this time, the role of vascular endothelial growth factor (VEGF) in neovascular AMD became obvious and anti-VEGF agents emerged for this purpose. Pegaptanib sodium intravitreal injection (Macugen; [OSI] Eyetech, New York, NY, 2004), ranibizumab intravitreal injection (Lucentis, Genentech, Inc., South San Francisco, CA, 2006) were the FDA approved treatments for AMD. The first report of intravitreal bevacizumab (Avastin; Genentech, Inc., South San Francisco, CA) administration for neovascular AMD was published in 2005 (Rosenfeld et al., 2005). By early 2006, off-label intravitreal bevacizumab was used by many retina specialists as a first-line therapy for neovascular AMD because of the low cost of this drug. Wholesale prices of the medications range from $\$ 1950$ per dose for ranibizumab and $\$ 995$ per dose for pegaptanib, to approximately $\$ 50$ per dose for bevacizumab (Champan \& Beckey, 2006; Web, 2008).

MARINA and ANCHOR were the first studies showing level 1 evidence for the effect of ranibizumab for the treatment of neovascular ARMD (Brown et al., 2009; Rosenfeld et al., 2006a; Rosenfeld et al., 2006b). These studies have shown that 33-40\% of the eyes with neovascular AMD treated with ranibizumab gained 15 letters or more (Brown et al., 2009; Rosenfeld et al., 2006a). However these studies used monthly injections of the drug for 24 months. This is the most effective treatment but almost impossible to apply in routine applications both for patients and doctors. Additionally monthly injections will cost so much that treatment cannot be afforded neither by patients nor the social security systems.

\section{How to decrease the number of injections without compromising visual acuity?}

PIER study was the first study investigating the results of less frequent dosing regimens with ranibizumab (3-monthly) for the treatment of AMD (Regillo et al., 2008). However 
PIER study revealed disappointing results showing loss of early gained vision during 3monthly injection period. Other prospective studies, PrONTO and SUSTAIN, investigated the efficacy of PRN (pro re nata; as needed) treatment regimen. Results from these studies suggested that fewer injections by using a variable dosing regimen with OCT will most likely result in visual acuity improvements similar to the results from the phase III trials which used monthly injections (Holz et al., 2011; Lalwani et al., 2009; Rosenfeld et al., 2006b)

\subsection{What is "PRN" treatment regimen and what are the most reliable criteria for treatment decision?}

PRN treatment regimen is a treatment schedule which allows treatment only if the lesion is active. The aim of the PRN treatment is to avoid monthly injections and to decrease the number of injections as much as possible while preserving the vision gained in the loading period (first three months).

The key point in PRN treatment is assessment of the activity of the lesion to decide for additional treatments. It is obvious that a totally fibrotic yellow scarring lesion without any hemorrhage around, only late staining of the scar tissue in fluorescein angiography (FA), and no subretinal or intraretinal fluid in optical coherence tomography (OCT) with stable vision for a long time does not need any treatment. On the other side of the spectrum, a lesion with subretinal hemorrhages all around, significant late leakage in FA and a considerable subretinal or intraretinal fluid in OCT and deteriorating vision recently needs treatment with no doubt. However most of the lesions are in between these two ends of the spectrum especially during the course of anti-VEGF treatments and may be difficult to decide if any further treatment is necessary or not.

Until recently, the presence or absence of fluorescein leakage and the angiographic appearance of the lesion were the main criteria for the decision to treat neovascular ARMD and re-treat using PDT or anti-VEGF therapy (Schmidt-Erfurth et al., 2007). Within the last decade OCT has emerged and enhanced our understanding in many central retinal diseases. For AMD, OCT appears to be useful for evaluating the responses of the retina and retinal pigment epithelium (RPE) to the treatment (Cohen et al., 2007; Eter \& Spaide, 2005; Fung et al., 2007; Krebs et al., 2008; Lalwani et al., 2009; Salinas-Alamán et al., 2005; Schmidt-Erfurth et al., 2007; van Velthoven et al., 2006;). Clinical trials have shown that in the two thirds of patients requiring ranibizumab therapy because of recurrent neovascularization, OCT seemed to detect early anatomic changes in the macula before any vision loss (observation during the extension trials of phase I-II studies by P. Rosenfeld: unpublished data). The PrONTO study was initiated to explore the use of OCT as the basis for a less frequent variable dosing regimen with ranibizumab (Fung et al., 2007; Lalwani et al., 2009). This study used some criteria for retreatment including an OCT based parameter (an increase in central OCT thickness of at least $100 \mathrm{~mm}$ ) during the first year. However they made an amendment to their OCT based criteria in the second year. They changed the retreatment criteria to include any qualitative change in the appearance of the OCT images that suggested recurrent fluid in the macula. These qualitative changes included the appearance of retinal cysts or subretinal fluid or an enlargement of a PED. Any of these qualitative changes alone was sufficient to permit retreatment (Lalwani et al., 2009). 


\subsection{Treatment regimens other than PRN}

Although PRN treatment regimen may reduce the number of intravitreal injections and allow the treatment plan to be individualized, it may still require monthly visits to specialized centers. In contrast to mandated monthly injections, patients treated with PRN strategies may develop multiple recurrences of $\mathrm{CNV}$ activity over time. Recurrent intra- or subretinal fluid could potentially induce progressive, cumulative dysfunction of the neural retina, resulting in a decreased ability of the retina to recover despite further treatment. There are some other treatment regimens like "treat and extend" and "individualized injection intervals" regimens which aim to individualize the treatment plan and decrease the number of injections per year, but at the same time attempts to achieve a fluid-free macula and decrease the number of visits (Brown \& Regillo, 2007; Gupta et al., 2010; Hörster et al., 2011; Oubraham et al., 2011; Spaide, 2007).

\subsubsection{Treat \& extend dosing regimen}

In an attempt to minimize the number of intravitreal injections, office visits, and ancillary testing, a "treat and extend" regimen (TER) was first put forth by Bailey Freund, (unpublished data, February 2006) and then adopted by others (Gupta et al., 2010; Oubraham et al., 2011). A typical TER starts with monthly injections until the signs of exudation have resolved with confirmation by OCT. The treatment interval is then sequentially lengthened by 1 to 2 weeks as long as there are no signs of recurrent exudation. When recurrent exudation is detected on a follow-up visit, the treatment interval is reduced to the prior interval. Treatment is rendered at every visit but the time between visits is individualized based on a given patient's response to treatment. As with traditional PRN regimens, the goal is to maintain an exudation-free macula with the fewest number of injections. This approach also may allow for a significant reduction in office visits and tests.

In a study by Gupta et al., eyes with neovascular AMD experienced significant visual improvement when managed with intravitreal ranibizumab using a TER. This treatment approach also was associated with significantly fewer patient visits, injections, and direct annual medical cost compared with monthly injections such as in the phase III clinical trials (Gupta et al., 2010). The interval was individualized for each patient in an attempt to maintain an exudation-free macula. In another study comparing the results of this treatment regimen with the standard PRN regimen, patients reinjected by the TER had a far better visual outcome than PRN regimen but needed more injections (Oubraham et al., 2011).

\subsubsection{Individualized injection intervals}

Another individualized treatment strategy that aims to avoid recurrent $\mathrm{CNV}$ activity in addition to reducing the number of injections and visits may be to perform the injection immediately prior to the next recurrence. This would require the ability to determine or predict the recurrence interval for an individual patient. A treatment schedule can be obtained for some of the cases after a couple of years of experience with PRN regimen (Hörster et al., 2011). Knowledge of individual recurrence interval times may allow for the development of an individualized treatment plan (Figure 1). 


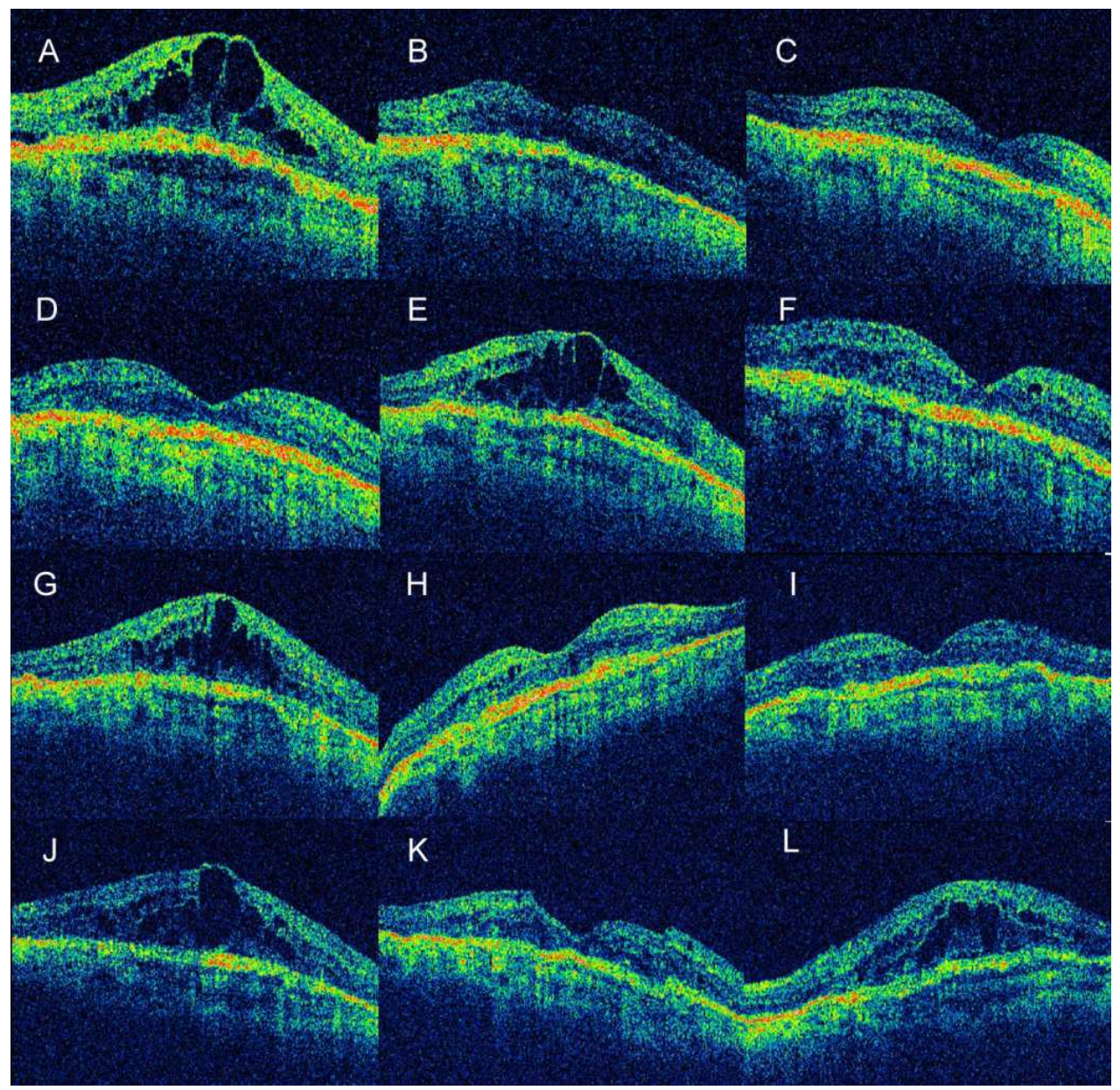

Fig. 1. A, Baseline, VA: 44 letters, 1st injection. B, 1st month, 53 letters, 2nd injection. C, 2nd month, 54 letters, $3^{\text {rd }}$ injection. D, 51 letters, no treatment. E, $4^{\text {th }}$ month, 46 letters, $4^{\text {th }}$ injection. $F$, $5^{\text {th }}$ month, 47 letters, no treatment. $G, 6^{\text {th }}$ month, 46 letters, $5^{\text {th }}$ injection. $H, 7^{\text {th }}$ month, 42 letters, $6^{\text {th }}$ injection. I, $8^{\text {th }}$ month, 50 letters, no treatment. J, $8^{\text {th }}$ month, 44 letters, $7^{\text {th }}$ injection. $K, 9^{\text {th }}$ month, 48 letters, no treatment. L, $10^{\text {th }}$ month, 38 letters, $8^{\text {th }}$ injection. According to the data, this patient has a recurrence pattern of 8 weeks, thus needs retreatment every 7 weeks.

A retrospective study in University of Cologne analyzed the recurrence intervals of patients undergoing anti-VEGF therapy for neovascular AMD to determine whether predictable, regular recurrence patterns were present for individual patients (Hörster et al., 2011). The paper reported that, all recurrences occurred at regular intervals in $41 \%$ of the eyes and the recurrence interval time may vary between individuals (Hörster et al., 2011). 
In conclusion, re-injections of ranibizumab shortly prior to a recurrence may avoid recurrent leakage and fluid accumulation, as well as further growth of the CNV lesion size. Therefore, avoiding recurrent $\mathrm{CNV}$ activity with prophylactic injections may protect the neural retina from additional damage and improve the long-term prognosis. However, this approach requires the ability to determine individual recurrence intervals with a couple of years of experience with PRN regimen.

\subsection{The need for an activity scoring for re-treatment of exudative AMD}

All treatment regimens mentioned above aims to reduce injection numbers without compromising the patients visual acuity. Yet there is not a consensus about the objective criteria of an active neovascular $\mathrm{CNV}$ lesion.

Definition of an active lesion should not be done only with the OCT based criteria. We believe that, other parameters like visual acuity, presence of hemorrhage associated with the lesion, lesion size and FA staining pattern (when needed) are all also important for assessment of neovascular AMD activity. The PrONTO study put some of these parameters together and created their criteria for retreatment. Retreatment with ranibizumab was performed only if one of the following occurred in PrONTO study (Fung et al., 2007):

1. An increase in central OCT thickness of at least $100 \mathrm{~mm}$,

2. A loss of five letters in conjunction with recurrent fluid by OCT,

3. New-onset classic neovascularization,

4. New macular hemorrhage.

SUSTAIN study used only VA and OCT criteria for retreatment decision. We believe that these are very well prepared criteria, however, some of the items could be changed and some new criteria could be added to make it more reliable.

\section{A clinical activity scoring for re-treatment of exudative AMD}

A new clinical activity scoring (AS) is proposed to assess activity of lesions, to quantify the activity for statistical purposes in clinical studies and to standardize the re-treatment protocols during the course of anti-VEGF treatments of neovascular AMD lesions. This may be a basis for treatment regimens.

\subsection{Methods}

The proposed AS is based on the well known and widely used signs and findings of active neovascular AMD (Table 1):

1. Presence of subretinal or intraretinal fluid in OCT,

2. Presence of hemorrhage associated with the lesion,

3. Change in vision;

a. Objective measured visual acuity (VA)

b. Subjective vision (what patient feels about his vision)

4. Change in size of the lesion,

5. FA staining pattern (when needed). 


\begin{tabular}{lll}
\hline PARAMETER & GRADING & SCORE \\
\hline Hemorrhage & No hemorrhage & 0 \\
Amount of hemorrhage & decreased & 1 \\
associated with the lesion & Same amount & 2 \\
& increased & 3 \\
\hline \multirow{2}{*}{ OCT } & None & 0 \\
Subretinal fluid / retinal & Decreased & 1 \\
thickening / PED & Any amount at beginning / Stable & 2 \\
& Increased & 3 \\
Visual assessment & Increased & 0 \\
Objective & No change & 1 \\
& Decreased & 2 \\
\hline \multirow{2}{*}{ Visual assessment } & Increased & 0 \\
Subjective & No change & 1 \\
& Decreased & 2 \\
\hline FA & No staining/window defect & 0 \\
Staining pattern & Staining of scar tissue/PED & 1 \\
\hline Size of the lesion & Late leakage & 2 \\
Lesion area in FA & Decreased & 0 \\
& Beginning size / Stable & 1 \\
\hline
\end{tabular}

Table 1. Clinical Activity Scoring for neovascular AMD lesions

Apart from FA staining pattern, all of the other assessments are based on the changes (samebaseline/increased/decreased) in each parameter and given a number to define the activity. At the end of the assessment, given numbers are summed and an activity score is calculated.

This scoring has been used in a group of neovascular AMD patients all of which have been involved in a prospective study for intravitreal bevacizumab (IVB) in our clinic (Şekeryapan et al., 2011). All of them received IVB monotherapy. The reports of the patients were reviewed retrospectively and demographic features as well as lesion characteristics of the patients were noted. AS of all of the lesions were calculated according to the following criteria:

1. OCT: OCT was performed using the Humphrey model 3000 (Zeiss-Humphrey Instruments, San Leandro, CA). After pupil dilatation, six consecutive $6 \mathrm{~mm}$ long scans containing 128 axial profiles (A-scans) at equally spaced angular orientations in a radial spoke pattern centered on the fovea (known as Fast Macular Thickness Protocol) were obtained for each eye. Using Retinal Thickness Mapping Software mean retinal thickness value which was measured in the central disc with a diameter of $1000 \mu \mathrm{m}$ in the center of the macula was used as central foveal thickness (CFT). The fluid pattern (subretinal / intraretinal diffuse / cystoid / pigment epithelial detachment - PED) was also noted. Only the CFT was used as an activity parameter in AS and at least $10 \%$ increase or decrease in CFT was accepted as a decrease or increase. The amount of fluid at the beginning was scored as 2 . It was scored as " 0 " if there is no fluid, " 1 " if there is a decrease and " 3 if there is an increase in CFT. 
2. Amount of hemorrhage: The amount of hemorrhage associated with the lesion (in ophthalmoscopy, colored fundus photography or FA) was noted and if there is any hemorrhage at the beginning it was scored as 2 . If there is no hemorrhage it was scored as 0 , if it was decreased it was scored as 1 , if it was the same, scored as 2 , and if it was increased scored as 3.

3. Visual assessment:

a. Objective VA is measured with ETDRS and noted as a baseline and scored as 1 . If there is a decrease in vision (any line or $\geq 5$ letters loss) it was scored as 2 and if there is any increase in vision (any line or $\geq 5$ letters gain) it was scored as 0 .

b. Subjective vision (what patient feels about his vision): Patient's feeling about any change in his vision was also asked and noted as subjective vision which was scored as 0 if he feels better, 2 if he feels worse and 1 if he did not feel any change (baseline).

4. FA staining pattern: No staining or window defect (0), staining of scar tissue or PED (1) and late leakage (2) were noted.

5. The area of the lesion $\left(\mathrm{mm}^{2}\right)$ : It was measured in FA and the baseline area (or no change) was scored as 1 , at least $10 \%$ (of the original area) increase was scored as 2 and at least $10 \%$ decrease was scored as 0 .

Records of the patients at the $1^{\text {st }}$ month visit after the treatment were also noted and all of the above parameters were again noted, so that an AS is calculated both before and after the treatment. AS could range between 0 and 14. Change in AS after the treatment was analyzed by using Wilcoxon signed rank test.

It can be hypothesized that, the more active the lesion the more it may respond to the antiVEGF therapy. A possible correlation between pretreatment AS and posttreatment decrease in AS was investigated by using Pearson correlation test to test this hypothesis.

Eyes with favorable treatment response (two or more units of decrease in AS) and unfavorable treatment response (one unit or no decrease in AS) were separated and the mean pre and posttreatment AS were calculated for both groups. The mean AS of these two groups were compared by using Mann-Whitney U test. At this stage, a cut off point for AS was searched to determine the eyes that need treatment. Sensitivity, specificity, negative and positive predictive values of the AS were calculated to determine the cut off point for AS which will be used to decide on re-treatments.

\subsection{Results}

In this section, the results of an ongoing study is presented to better understand the activity scoring.

A total of 52 eyes with neovascular AMD were involved in the study. Mean age of the patients was 72.7 (52-89), mean visual acuity (logMAR) was $0.68(0-1.6)$ and mean lesion area was $8.9 \mathrm{~mm}^{2}\left(0.6-33 \mathrm{~mm}^{2}\right)$ before treatment.

Pretreatment mean AS of eyes was 7.4 (ranged between 3 and 10) which decreased significantly to 4.2 after treatment $(\mathrm{p}<0.001$, Wilcoxon). There was a significant positive correlation between the pretreatment AS of eyes and the posttreatment decrease in AS (Pearson correlation coefficient: 0.534, $\mathrm{p}<0.001$, Figure 2). 


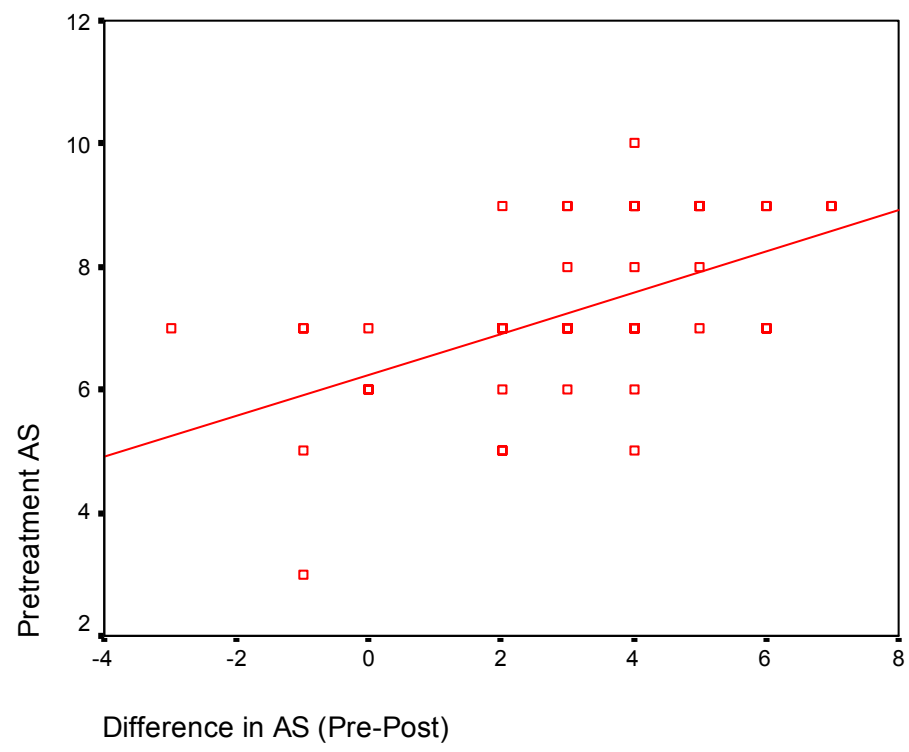

Fig. 2. Correlation between the pretreatment AS of eyes and the post-treatment decrease in AS (Pearson correlation coefficient: 0.534, $\mathrm{p}<0.001$ )

To define a cut-off point a group of eyes with favorable treatment responses is formed by separating those who had at least 2 point decrease in AS and named the favorable response group. The remaining eyes formed the unfavorable response group. The pretreatment mean AS was 7.5 (6-10) in favorable response group and 6 (3-7) in unfavorable response group. The pretreatment AS in favorable treatment response group was statistically significantly higher than those of unfavorable treatment response groups ( $p=0.003$, Figure 3 ).

The sensitivity, specificity, negative and positive predictive values of the AS with different cut off points were calculated (table 2) and an AS of 7 was found to be most suitable as a cutoff point for further analysis.

\begin{tabular}{llll}
\hline & $\begin{array}{l}\text { Pretreatment } \\
\text { AS } \geq 6\end{array}$ & $\begin{array}{l}\text { Pretreatment } \\
\text { AS } \geq 7\end{array}$ & $\begin{array}{l}\text { Pretreatment } \\
\text { AS } \geq 8\end{array}$ \\
\cline { 2 - 4 } Positive predictive value & $85,10 \%$ & $90,20 \%$ & $100,00 \%$ \\
Negative predictive value & $40,00 \%$ & $45,50 \%$ & $25,70 \%$ \\
Sensitivity & $93,00 \%$ & $86,00 \%$ & $39,50 \%$ \\
Specificity & $22,20 \%$ & $55,60 \%$ & $100,00 \%$ \\
\hline
\end{tabular}

Table 2. Predictive values, sensitivity and specificity of AS for detecting favorable treatment response (2 or more decrease in AS)

Eyes with an AS of 7 or more (group 1, highly active group, n=41) were separated from those less than 7 (group 2, less active group, $n=11$ ) and a subgroup analysis was done. The mean AS in group 1 was 7.8 (7-10) before treatment and 4.3 (1-10) after treatment. The 
decrease was statistically significant $(\mathrm{p}<0.001$, Figure 4$)$. The mean pretreatment AS was 5.4 (3-6) in group 2 which decreased to 4 (1-6) after treatment. Although the decrease was less than that in group 1 , it was still statistically significant $(p=0.034$, Figure 4$)$. The mean decrease in AS was 3.5 in group one and 1.4 in group two ( $p=0.003$, Figure 5).

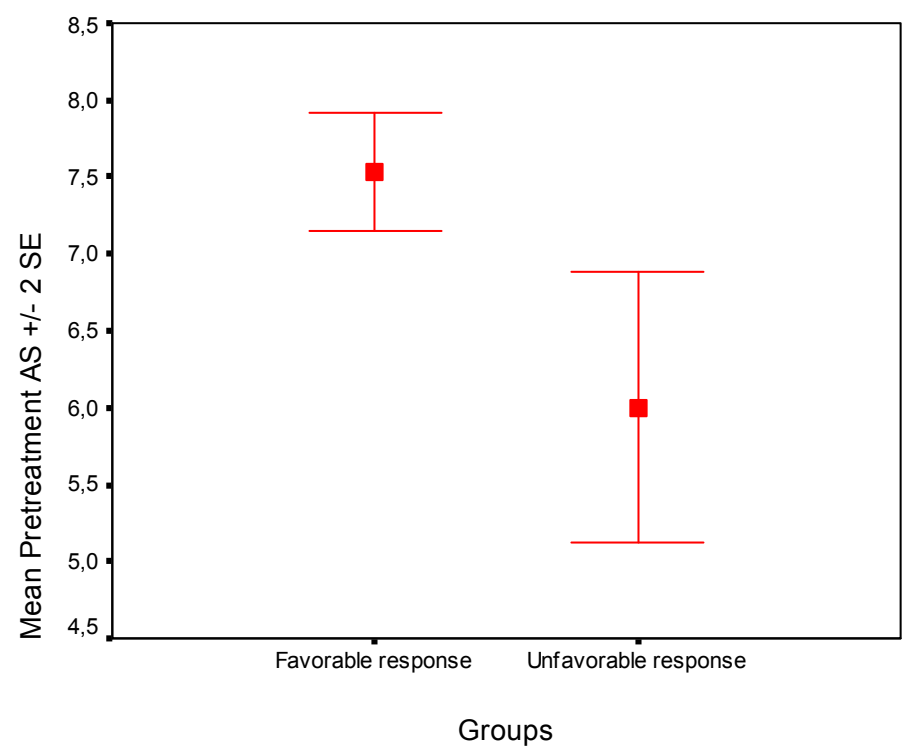

Fig. 3. The pretreatment AS was statistically significantly higher in favorable treatment response group than unfavorable treatment response group (Mann Whitney $U$ test $p=0.003$ ).

Sensitivity of AS (ratio of eyes with a favorable response and an AS of 7 or more to the total number of eyes with favorable response) was $86 \%$ and, specificity of AS (ratio of eyes with an unfavorable response and an AS of less than 7 to the total number of eyes with unfavorable response) was $56 \%$ with a cut-off point of 7 (table 3 ). Positive predictive value (ratio of eyes with AS of 7 or more and a favorable response to the total number of eyes with AS of 7 or more) of AS was $90 \%$ and negative predictive value (ratio of eyes with AS of less than 7 and an unfavorable response to the total number of eyes with AS of less than 7) of AS was $45 \%$ (table 3). These may be assumed as indicators for accuracy of AS.

\begin{tabular}{llll}
\hline & Favorable Response & Unfavorable Response & Total \\
\cline { 2 - 4 } AS $\geq 7$ & 37 & 4 & 41 \\
AS $<7$ & 6 & 5 & 11 \\
Total & 43 & 9 & 52 \\
\hline
\end{tabular}

Positive predictive value, 37 of $41=90 \%$; negative predictive value, 5 of $11=45 \%$, sensitivity, 37 of $43=86 \%$, specificity, 5 of $9=56 \%$.

Table 3. Accuracy of activity score (AS) in predicting therapeutic outcome of treatment in neovascular AMD. 


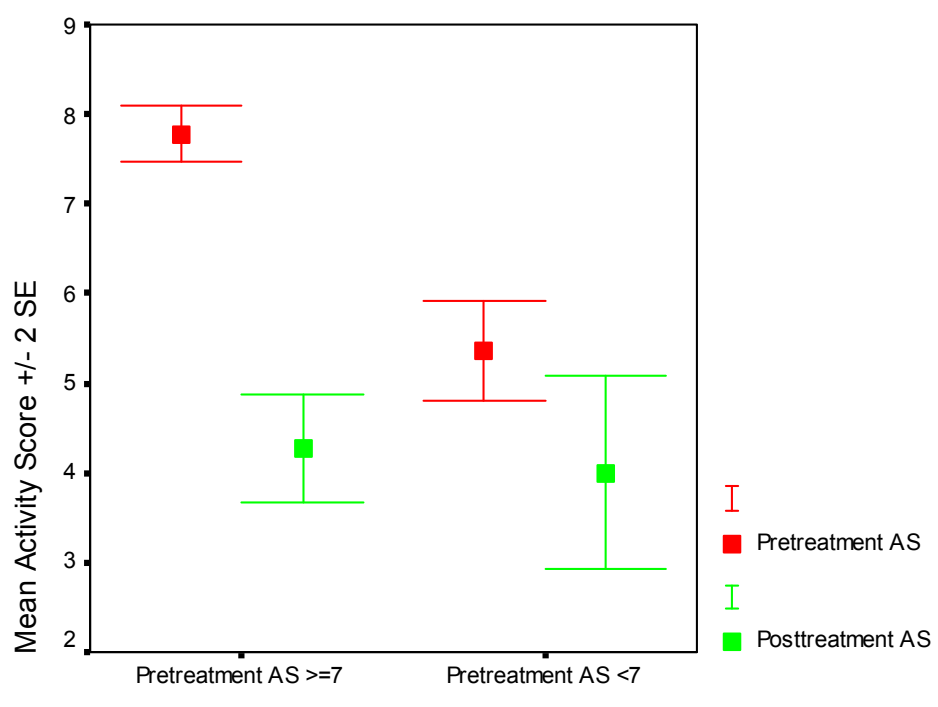

Cut-off AS

Fig. 4. Pretreatment and posttreatment mean AS of eyes in group 1 (with an AS of 7 or more, highly active group) and in group 2 (with an AS of less than 7, less active group).

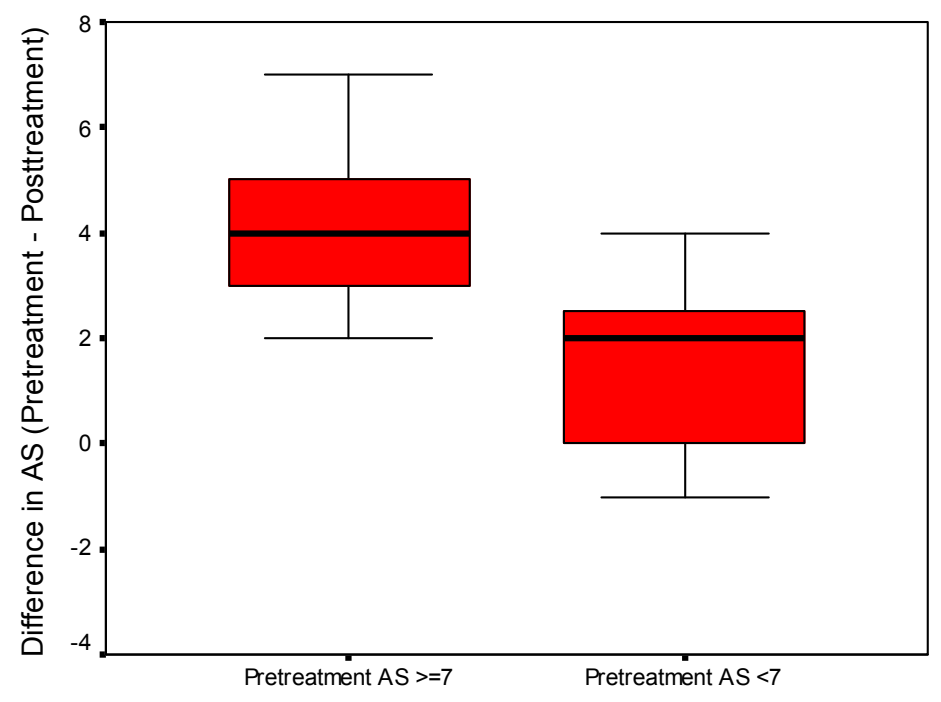

\section{Cut-off AS}

Fig. 5. Pre and post treatment difference in AS of highly active group and less active group. Decrease in AS was significantly more in highly active group (pretreatment $A S \geq 7)(p=0.003)$. 


\section{Discussion}

Neovascular AMD activity is an important factor to determine if it should be treated or not. It is important not to over-treat these eyes to avoid from injection and drug related complications as well as high cost of the treatment. There is no standard protocol for the treatment and retreatment schedule of these eyes and most ophthalmologists use their clinical experience to decide. Following the disappointing results from the quarterly regimen of the PIER study, which showed us loss of early gained vision during 3-monthly injection period (Regillo et al., 2008), new prospective studies like PrONTO, and SUSTAIN are under way investigating less frequent dosing regimens and preliminary results from these studies suggest that fewer injections (mean: 9.9 injections within 24 months in PrONTO, 5.7 injections within 12 months in SUSTAIN) will most likely result in visual acuity improvements similar to the results from the phase III trials by using a variable dosing regimen with OCT (Fung et al., 2007; Lalwani et al., 2009; Rosenfeld et al., 2006b).

Although most of the studies used OCT findings and VA changes to determine the need for additional therapy (Holz et al., 2011), we believe that, some other parameters like, subjective feeling of patients about their vision, presence of hemorrhage associated with the lesion, lesion size, FA staining pattern and are also important for assessment of neovascular AMD activity especially in those undetermined cases. AS is defined to standardize the understanding of findings and definition of active lesion. We are studying on this system since 2002 and have used it in our practice as well as in some of our studies (Ozdek et al.,2005; Ozdek et al.,2007).

It is obvious that ophthalmoscopic appearance of a lesion is very important during interpretation of OCT and FA findings. This is to see new subretinal hemorrhages, exudates and fibrotic scar tissues so that FA and OCT findings can correctly be interpreted. OCT is a very important indicator of neovascular AMD activity and may be assumed as the main determinant for deciding the need for re-treatment in patients with AMD. Recently, there is a tendency to assess the activity of neovascular AMD lesions with only OCT without performing FA after the initial assessment (Brown \& Regillo, 2007; Cohen et al., 2007; Rosenfeld et al., 2006b; Salinas-Alamán et al., 2005). This approach has emerged especially after anti-VEGF treatments of neovascular AMD lesions to avoid from monthly FA. Once the diagnosis of neovascular AMD was established with FA before treatment, OCT was reported to have a sensitivity of $96 \%$ for detecting lesion activity and a diagnostic efficiency (proportion of correct results) of 83\% (Salinas-Alamán et al., 2005). However, OCT cannot detect other features including blood, lipid, and vascular patterns so effectively. When a subretinal new hemorrhage associated with the lesion appears in an eye with a dry OCT and FA (without any late leakage) most of the retina specialists assume it as an active lesion and treat it. This is the case when activation takes place on a far edge of the subfoveal neovascular AMD lesion. Salinas et al reported that, OCT may be complementary to FA, especially in cases in which FA was inconclusive. They have found that OCT was considered as positive (presence of sub-retinal fluid and/or intraretinal fluid) in $14.2 \%$ of the cases in which FA did not show clear leakage. On the other hand, most of the cases with positive OCT findings without any leakage on FA (false positives) had a disciform scar with persistent cystic cavities on OCT (Salinas-Alamán et al., 2005). It can be concluded that if there is no fibrotic scar visible during the fundus examination, the presence of remaining 
fluid on the OCT scan may indicate residual lesion activity. It is also valid to assume that a hyperreflective structure on OCT could be misinterpreted without a fundus examination. Therefore, we believe that OCT, FA, and a fundus examination are complementary examinations that should be interpreted together in those undetermined cases.

Although we used FA as a parameter in AS, we do not mean to say that we have to perform FA at every visit. Actually, we need to score the lesion only if it is not so clear that the lesion is active or not what we call as "undetermined cases"(Figure 6). In other words, if we are not sure that a patient should be retreated or not, we can apply to the AS just to bring all the parameters together. If we still do not want to perform a FA, we can add only 1 point for FA which is neutral for activity scoring for FA.

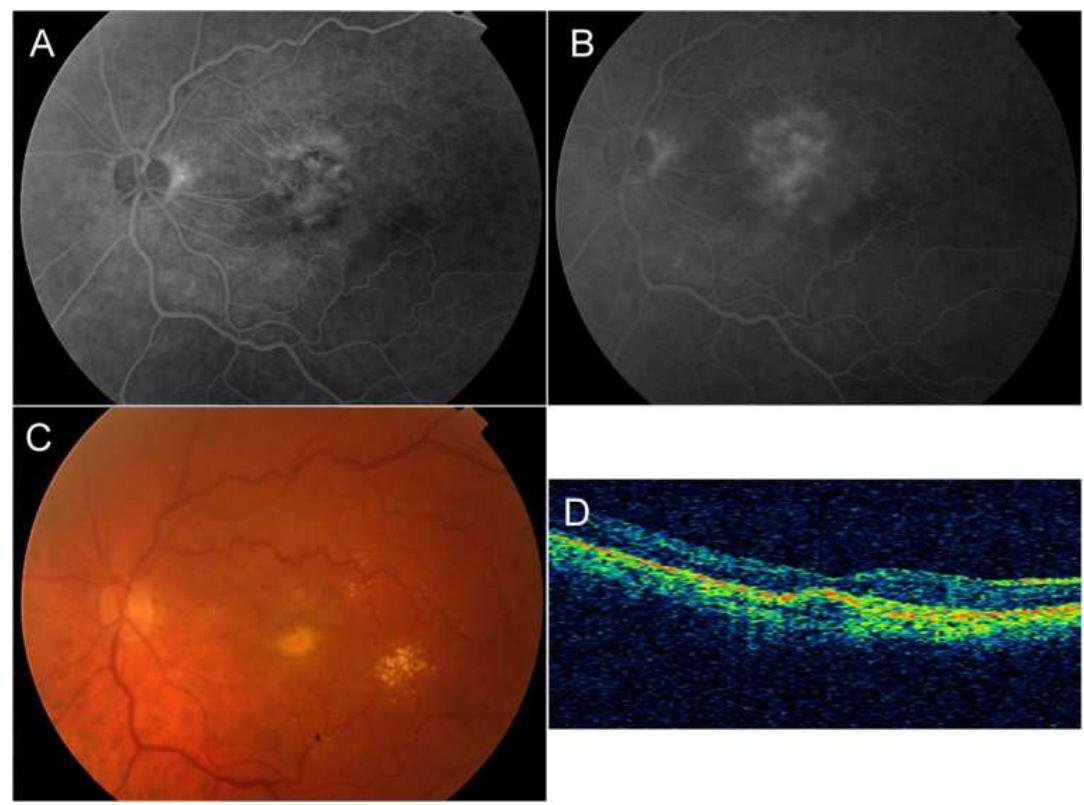

Fig. 6. 85 year old woman with a neovascular AMD on the left eye received four doses of intravitreal bevacizumab. On the last visit she had lost 5 letters with a subjective visual impairment. A, early phase of the angiogram. B, late phase of the angiogram. C, fundus photograph. D, OCT image of fovea. This would be an undetermined case without FA. Although the OCT has no sign of active lesion, there are late leakage in FA and objective and subjective visual loss. According to table 1 the patient has an activity score of 8 and assessed as an active lesion.

Change in VA is another very important determinant factor in assessment of treatment effect on neovascular AMD. Usually worsening of VA is a sign of bad response to the treatment and, a stable or increased VA is supposed as a favorable treatment response. It is possible to see patients with a dry OCT and silent ophthalmoscopy without any hemorrhage having a decreased VA both objectively and subjectively. Those patients may have a late leakage in FA indicating activity and treatment need or that VA decrease may be a sign of progression of dry component of AMD. 
Vision is not only the central VA and it has many other components like scotomas in visual field, contrast sensitivity, color vision etc. So snellen or ETDRS visual acuity measurement may not be enough to assess vision especially in macular diseases. The simplest measure may be to ask the patient his feelings about his vision; if it is the same, decreased or increased. The subjective change in vision may also give important clues about the effect of treatment. However, it is highly dependent on the patients' personality and on the eye (in the better eye or in the worse eye). Patient may feel always worse if he is pessimistic and depressive or vice versa. Patient may feel the changes more precisely if the problem is in the better eye, on the other hand, may not feel the significant changes if the disease is in the worse eye. To overcome such shortcomings of subjective assessment of vision, more objective measures for the assessment of the other components of the central vision may be used. VFQ25 may be an option but takes a long time for these cases and is not so practical. Unver et al have developed a new tool for the automated assessment of functional central vision called central field acuity perimetry to solve such problems (Unver et al., 2009). However there is no clinical study with central field acuity perimetry for this purpose up till now. Microperimetry and functional magnetic resonance imaging are other new tools to measure objective measure of topographic visual function (Baseler et al., 2011; Uppal et al., 2011). On the other hand, deterioration of vision is not always an indication of lesion activity itself. Progression of the dry component of the disease (atrophic changes), fibrosis and cicatrisation of the lesion during healing period following treatment may also cause deterioration of vision. Vision cannot be a sole criterion (just like other parameters) but may add to other factors indicating lesion activity.

Change in lesion area is another important determinant of the activity of the lesion. It is not seldom to see a central inactive lesion without any fluid in OCT or any change in objective measured VA may enlarge with a pseudo-pod like extension from one side indicating an active lesion. They usually feel this difference as a subjective worsening of the vision. On the other side, the lesion area may become smaller after treatment indicating a decreased activity of the lesion. This is also an important complementary parameter for assessment of lesion activity and the response to treatment that needs to be taken into account during assessment especially in those gray cases.

The major problem that we faced during the assessment of the reliability of this scoring system was the absence of a gold standard to define an active lesion which can be used for comparison. Rosenfeld et al were the first to define some criteria to identify an active lesion which needs retreatment with anti-VEGF agents in PrONTO study (Ozdek et al., 2005; Rosenfeld et al., 2006b). However, these criteria were not tested for reliability or sensitivity. Our scoring system has some differences from the criteria used in PrONTO study. Firstly, we used a $10 \%$ change in CFT in OCT to be significant instead of 100 micron increase for all cases. Sometimes only 30 microns of increase in CFT may be an important change (especially in minimally edematous fovea) on the other hand, even 100 microns of increase in OCT may be meaningless (especially in highly edematous/elevated fovea). Secondly, we have added change in size of the lesion as another criterion. Thirdly, we used subjective changes in vision as another criterion to decide on retreatments. This is because most of the patients feel some very early changes in lesion activity before any change become apparent 
in FA, OCT or ETDRS visual acuity testing. We strongly believe that this should be taken into account during assessment of lesion activity.

We would like to emphasize on the unequal distribution of points between different parameters of the AS. We have purposefully given higher scores for hemorrhage (3 points), OCT ( 3 points) and VA ( $2+2$ points) which are more powerful indicators of the lesion activity than the FA and lesion size.

When we take all of these parameters into account and score it, we observed that pretreatment mean AS was 7.4 which decreased significantly to 4.2 after treatment. Which means that AS really indicates the activity of the lesion. We also observed that a lesion with a higher AS is more likely to give more dramatic response to the anti-VEGF treatment with a more significant decrease in AS (Figure 4).

Transferring these data to the clinical applications, it seems logical to treat lesions with an AS of 7 or more with anti-VEGF therapy. The high sensitivity $(86 \%)$ and positive predictive values $(90 \%)$ of the AS strongly suggest retreatment of lesions with an AS of 7 or more. However the lower sensitivity and negative predictive values of AS weakly supports observation of the ones with lower AS without treatment. The lower rates are most possibly because of the lower number of the eyes with less AS who had still been treated with antiVEGF. When the number of such eyes had been equal to the treated eyes with higher AS, the specificity and negative predictive values of AS might have been higher which would make the AS a more reliable measure.

In addition to routine clinical practice, AS may be used as a standard way of assessment of lesion activity especially in clinical studies for the statistical comparison of the results. AS may be a valuable tool to see the picture (both the lesion and the response to the treatment) as a whole.

\section{Conclusions}

In conclusion, assessment of the lesion activity is important for PRN treatment approaches and AS seems to be a standardized measure to assess the activity of the lesion at the beginning as well as the treatment effect after anti-VEGF therapy. It may be modified with use of some other tools like central field acuity perimetry to be more objective. A lesion with an AS of 7 or more seems to be an active lesion which needs treatment and it most possibly will give a favorable response to anti-VEGF treatment as a decrease in activity. However, the sensitivity and specificity of AS needs to be tested with further studies with larger number of patients to be conclusive. Additionally scoring of the lesion activity quantifies the lesion activity allowing for statistical comparisons between different treatment methods in clinical studies.

Individualized approaches, on the other side, may be a good option in suitable cases. Reinjections shortly prior to a recurrence may avoid further growth of the CNV lesion size, protecting the neural retina from additional damage and improve the long-term prognosis. This may be a better option than PRN approaches preventing recurrences other than treating the recurrence. However, this approach requires the ability to determine 
individual recurrence intervals with a couple of years of experience with PRN regimen and some lesions do not obey any rule of periodical recurrence in long term. The results of these approaches need to be proven with further randomized controlled studies to be conclusive.

\section{References}

Baseler HA, Gouws A, Crossland MD, Leung C, Tufail A, Rubin GS \& Morland AB, (2011). Objective Visual Assessment of Antiangiogenic Treatment for Wet Age-Related Macular Degeneration. In: Optom Vis Sci., e-pub, June 2011, Available from: <http://www.ncbi.nlm.nih.gov/pubmed/21705938>

Brown DM \& Regillo CD, (2007). Anti-VEGF agents in the treatment of neovascular agerelated macular degeneration: applying clinical trial results to the treatment of everyday patients. Am J Ophthalmol., Vol.144, No.4, (October 2007), pp.627-37, ISSN 0002-9394

Brown DM \& Regillo CD, (2007). Anti-VEGF agents in the treatment of neovascular agerelated macular degeneration: applying clinical trial results to the treatment of everyday patients. Am J Ophthalmol., Vol.144, No.4, (October 2007), pp.627-37, ISSN 0002-9394

Brown DM, Michels M, Kaiser PK, Heier JS, Sy JP \& Ianchulev T, ANCHOR Study Group, (2009). Ranibizumab versus verteporfin photodynamic therapy for neovascular age-related macular degeneration: Two-year results of the ANCHOR study. Ophthalmology. Vol.116, No.1, (January 2009), pp.57-65.e5, ISSN 0161-6420

Chapman JA \& Beckey C, (2006). Pegaptanib: a novel approach to ocular neovascularization. Ann Pharmacother., Vol.40, No.7-8, (July-August 2006), pp.13226, ISSN 1060-0280

Cohen SY, Korobelnik JF, Tadayoni R, Coscas G, Creuzot-Garcher C, Devin F, Gaudric A, Mauget-Faysse M, Sahel JA, Souied E, Weber M \& Soubrane G, (2007). Monitoring anti-VEGF drugs for treatment of exudative AMD. J Fr Ophtalmol, Vol.30, No.4, (April 2007), pp.330-4, ISSN 0181-5512

Eter N \& Spaide RF, (2005). Comparison of fluorescein angiography and optical coherence tomography for patients with choroidal neovascularization after photodynamic therapy. Retina, Vol.25, No.6, (September 2005), pp.691-6, ISSN 0275004X

Ferris FL III, Fine SL \& Hyman L, (1984). Age-related macular degeneration and blindness due to neovascular maculopathy. Arch Ophthalmol., Vol.102, No. 11, (November 1984), pp.1640-2, ISSN 0003-9950

Friedman DS, O'Colmain BJ, Muñoz B, Tomany SC, McCarty C, de Jong PT, Nemesure B, Mitchell P \& Kempen J, Eye Diseases Prevalence Research Group, (2004). Prevalence of agerelated macular degeneration in the United States. Arch Ophthalmol., Vol.122, No.4, (April 2004), pp.564 -72, ISSN 0003-9950 Friedman et al., 2004

Fung AE, Lalwani GA, Rosenfeld PJ, Dubovy SR, Michels S, Feuer WJ, Puliafito CA, Davis JL, Flynn HW Jr \& Esquiabro M, (2007). An optical coherence tomography-guided, 
variable-dosing regimen with intravitreal ranibizumab (Lucentis) for neovascular age-related macular degeneration. Am J Ophthalmol. Vol.143, No.4, (April 2007), pp.566-583, ISSN 0002-9394

Gupta OP, Shienbaum G, Patel AH, Fecarotta C, Kaiser RS \& Regillo CD, (2010). A treat and extend regimen using ranibizumab for neovascular age-related macular degeneration clinical and economic impact. Ophthalmology, Vol.117, No.11, (November 2010), pp.2134-40, ISSN 0161-6420

Holz FG, Amoaku W, Donate J, Guymer RH, Kellner U, Schlingemann RO, Weichselberger A \& Staurenghi G, SUSTAIN Study Group, (2011). Safety and efficacy of a flexible dosing regimen of ranibizumab in neovascular age-related macular degeneration: the SUSTAIN study. Ophthalmology, Vol.118, No.4, (April 2011), pp.663-71, ISSN 0161-6420

Hörster R, Ristau T, Sadda SR \& Liakopoulos S, (2011). Individual recurrence intervals after anti-VEGF therapy for age-related macular degeneration. Graefes Arch Clin Exp Ophthalmol., Vol.249, No.5, (May 2011), pp.645-52, ISSN 0721-832X

Klein R, Klein BE \& Linton KL, (1992). Prevalence of age-related maculopathy: the Beaver Dam Eye Study. Ophthalmology, Vol.99, No.6, (June 1992), pp.933-43, ISSN 01616420

Krebs I, Ansari-Shahrezaei S, Goll A \& Binder S, (2008). Activity of neovascular lesions treated with bevacizumab: comparison between optical coherence tomography and fluorescein angiography. Graefes Arch Clin Exp Ophthalmol., Vol.246, No.6, (June 2008), pp.811-5, ISSN 0721-832X

Lalwani GA, Rosenfeld PJ, Fung AE, Dubovy SR, Michels S, Feuer W, Davis JL, Flynn HW Jr \& Esquiabro M, (2009). A variable-dosing regimen with intravitreal ranibizumab for neovascular age-related macular degeneration: year 2 of the PrONTO Study. Am J Ophthalmol., Vol.148, No.1, (July 2009), pp.43-58.e1, ISSN 0002-9394

Oubraham H, Cohen SY, Samimi S, Marotte D, Bouzaher I, Bonicel P, Fajnkuchen F \& Tadayoni R, (2011). Inject and extend dosing versus dosing as needed: a comparative retrospective study of ranibizumab in exudative age-related macular degeneration. Retina, Vol.31, No.1, (January 2011), pp.26-30, ISSN 0275004X

Ozdek S, Bozan E, Gurelik G \& Hasanreisoglu B, (2007). Transpupillary thermotherapy for the treatment of choroidal neovascularization secondary to angioid streaks. Can J Ophthalmol., Vol.42, No.1, (February 2007), pp.95-100, ISSN 0008-4182

Ozdek S, Hondur A, Gurelik G \& Hasanreisoglu B, (2005). Transpupillary t hermotherapy for myopic choroidal neovascularization: 1-year follow-up: TTT for myopic CNV. Int Ophthalmol., Vol.26, No.4-5, (August-October 2005), pp.127-33, ISSN 0165-5701

Regillo CD, Brown DM, Abraham P, Yue H, Ianchulev T, Schneider S \& Shams N (2008). Randomized, double-masked, sham-controlled trial of ranibizumab for neovascular age-related macular degeneration: PIER Study year 1. Am J Ophthalmol., Vol.145, No.2, (February 2008), pp.239-48, ISSN 0002-9394 
Rosenfeld PJ, Brown DM, Heier JS, Boyer DS, Kaiser PK, Chung CY \& Kim RY, MARINA Study Group, (2006). Ranibizumab for neovascular age-related macular degeneration. New England Journal of Medicine, Vol.355, No.14, (October 2006), pp.1419-31, ISSN 0028-4793

Rosenfeld PJ, Moshfeghi AA \& Puliafito CA, (2005). Optical coherence tomography findings after an intravitreal injection of bevacizumab (Avastin) for neovascular age-related macular degeneration. Ophthalmic Surg Lasers Imaging., Vol.36, No.4, (July-August 2005), pp.331-5, ISSN 1542-8877

Rosenfeld PJ, Rich RM \& Lalwani GA, (2006). Ranibizumab: Phase III clinical trial results. Ophthalmol Clin North Am., Vol.19, No.3, (September 2006), pp.361-72, ISSN 08961549

Salinas-Alamán A, García-Layana A, Maldonado MJ, Sainz-Gómez C \& Alvárez-Vidal A, (2005). Using optical coherence tomography to monitor photodynamic therapy in age related macular degeneration. Am J Ophthalmol., Vol.140, No.1, (July 2005), pp.23-8, ISSN 0002-9394

Schmidt-Erfurth UM, Richard G, Augustin A, Aylward WG, Bandello F, Corcòstegui B, Cunha-Vaz J, Gaudric A, Leys A, Schlingemann RO; European Society for Retina Specialists' Guidelines Committee (EURETINA), (2007). Guidance for the treatment of neovascular age-related macular degeneration. Acta Ophthalmologica Scandinavica, Vol.85, No.5, (August, 2007), pp.486-94, ISSN 13953907

Spaide R. Ranibizumab according to need: a treatment for age-related macular degeneration. Am J Ophthalmol. Vol.143, No.4, (April 2007), pp.679-80, ISSN 00029394

Şekeryapan B, Özdek Ş, Özmen MC, Gürelik G \& Hasanreisoğlu B, (2011). Yaşa Bağlı Maküla Dejenerasyonuna Bağlı Koroidal Neovaskülarizasyon Tedavisinde Tek Başına Bevacizumab veya Fotodinamik Tedavi ile Kombinasyon: 12 Ay Sonuçları. Retina-Vitreus, Vol.19, No.2, (June 2011), pp.97-102, ISSN 1300-1256

Unver YB, Yavuz GA, Bekiroğlu N, Presti P, Li W \& Sinclair SH, (2009). Relationships between clinical measures of visual function and anatomic changes associated with bevacizumab treatment for choroidal neovascularization in age-related macular degeneration. Eye, Vol.23, No.2, (February 2009), pp.453-60, ISSN 0950$222 X$

Uppal G, Feely M, Crossland M, Membrey L, Lee J, da Cruz L \& Rubin GS, (2011). Assessment of Reading Behaviour with an Infrared Eyetracker after 360 Degree Macular Translocation for Age Related Macular Degeneration. Invest Ophthalmol Vis Sci., Vol.52, No.9, (August 2011), pp.6486-96, ISSN 1552-5783

van Velthoven ME, de Smet MD, Schlingemann RO, Magnani M \& Verbraak FD, (2006). Added value of OCT in evaluating the presence of leakage in patients with age-related macular degeneration treated with PDT. Graefes Arch Clin Exp Ophthalmol., Vol.244, No.9, (September 2006), pp.1119-23, ISSN 0721$832 X$ 
Web JA. (January 2008). Genentech decision expands access to bevacizumab. In: Ophthalmology Times, 2011, Available from:

<http://ophthalmologytimes.modernmedicine.com/ophthalmologytimes/issue/is sueDetail.jsp?id=13920>. 


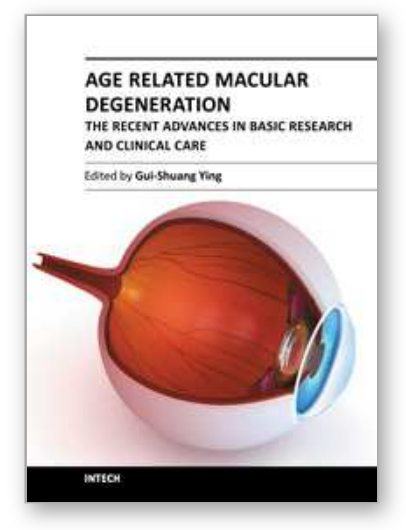

\author{
Age Related Macular Degeneration - The Recent Advances in Basic \\ Research and Clinical Care \\ Edited by Dr. Gui-Shuang Ying
}

ISBN 978-953-307-864-9

Hard cover, 300 pages

Publisher InTech

Published online 20, January, 2012

Published in print edition January, 2012

Age-related Macular Degeneration (AMD) is the leading cause of vision loss and blindness in the developed countries. In the past decade, great progress has been made in understanding the pathobiology and genetics of this blinding disease, as well as in finding new therapies for its treatment. These include the discovery of several genes that are associated with the risk of AMD, new anti-VEGF treatments for wet AMD and new imaging techniques to diagnose and monitor the AMD. All chapters in this book were contributed by outstanding research scientists and clinicians in the area of AMD. I hope this timely book will provide the basic scientists and clinicians with an opportunity to learn about the recent advances in the field of AMD.

\title{
How to reference
}

In order to correctly reference this scholarly work, feel free to copy and paste the following:

Sengul Ozdek and Mehmet Cuneyt Ozmen (2012). Re-Treatment Strategies for Neovascular AMD: When to Treat? When to Stop?, Age Related Macular Degeneration - The Recent Advances in Basic Research and Clinical Care, Dr. Gui-Shuang Ying (Ed.), ISBN: 978-953-307-864-9, InTech, Available from:

http://www.intechopen.com/books/age-related-macular-degeneration-the-recent-advances-in-basic-researchand-clinical-care/re-treatment-strategies-for-neovascular-amd-when-to-treat-when-to-stop-

\section{INTECH}

open science | open minds

\author{
InTech Europe \\ University Campus STeP Ri \\ Slavka Krautzeka 83/A \\ 51000 Rijeka, Croatia \\ Phone: +385 (51) 770447 \\ Fax: +385 (51) 686166 \\ www.intechopen.com
}

\author{
InTech China \\ Unit 405, Office Block, Hotel Equatorial Shanghai \\ No.65, Yan An Road (West), Shanghai, 200040, China \\ 中国上海市延安西路65号上海国际贵都大饭店办公楼405单元 \\ Phone: +86-21-62489820 \\ Fax: $+86-21-62489821$
}


(C) 2012 The Author(s). Licensee IntechOpen. This is an open access article distributed under the terms of the Creative Commons Attribution 3.0 License, which permits unrestricted use, distribution, and reproduction in any medium, provided the original work is properly cited. 